\title{
Chemistry, bioactivities, extraction and analysis of azadirachtin: State-of-the-art
}

\author{
Sara R. Fernandes ${ }^{\mathrm{a}, \mathrm{b}}$, Luisa Barreiros ${ }^{\mathrm{a}, \mathrm{b}}$, Rita F. Oliveira ${ }^{\mathrm{a}, \mathrm{c}}$, Agostinho Cruz $^{\mathrm{a}}$, \\ Cristina Prudêncio $^{\mathrm{d}, \mathrm{e}}$, Ana Isabel Oliveira ${ }^{\mathrm{a}}$, Cláudia Pinho ${ }^{\mathrm{a}}$, Nuno Santos ${ }^{\mathrm{f}}$, Joaquim Morgado ${ }^{\mathrm{g}}$ \\ ${ }^{a}$ Centro de Investigação em Saúde e Ambiente, Escola Superior de Saúde, Instituto Politécnico do Porto, Porto, Portugal \\ ${ }^{\mathrm{b}}$ LAQV, REQUIMTE, Departamento de Ciências Químicas, Faculdade de Farmácia, Universidade do Porto, Porto, Portugal \\ ${ }^{\mathrm{c}}$ Secção Autónoma de Ciências da Saúde, Universidade de Aveiro, Aveiro, Portugal \\ ${ }^{\mathrm{d}}$ Ciências Químicas e das Biomoléculas, Escola Superior de Saúde, Instituto Politécnico do Porto, Porto, Portugal \\ e $i 3 S$ - Instituto de Investigação e Inovação em Saúde, Universidade do Porto, Porto, Portugal \\ ${ }^{\mathrm{f}}$ AustroCel Hallein GmbH, Hallein, Austria \\ ${ }^{g}$ Bio4Life4You, Porto, Portugal
}

\begin{abstract}
A B S T R A C T
Azadirachta indica A. Juss. (Neem) is an Indian tree recognized for its activity as pesticide, as well as several pharmacological properties. Among the various compounds already isolated and studied from Neem tree, azadirachtin (AZA) was identified as the main bioactive compound. Azadirachtin can be found at different parts of the Neem plant but assumes its maximum concentration at the seed level. This compound features a quite complex chemical structure, which justifies the 20-plus-year difficulty to identify the synthetic pathway that subsequently permitted to carry out its artificial synthesis. Azadirachtin is widely used as a basis for production of biopesticides; nevertheless, other properties have been recognized for this substance, among which the an-ticancer and antimalarial activity stand out. The methods available for azadirachtin extraction are diverse, including solid-liquid extraction and extraction with solvents at high or low temperatures. Alcohol based solvents are associated with higher extraction yields and are therefore preferred for the isolation of azadirachtin from plant parts. Clean-up of the extracts is generally required for further purification. The highest azadirachtin levels have been obtained from Neem seeds but concentration values present a large variation between batches. Therefore, in addition to extraction procedures, it is essential to establish routine methods for azadirachtin identification and quantification. Chromatography-based techniques are preferably selected for detection and quantification of azadirachtin in plant matrices. Overall, this process will guarantee a future reproducible, safe and effective use of the extracts in formulations for commercial applications.
\end{abstract}

Keywords: Azadirachta indica; Neem; Bioactive compounds; Chemical characterization; Extraction Quantification

\section{Introduction}

Since primitive times, humans have been searching in nature for resources that permit to improve life conditions and, consequently, prolong life span. Some of the plants emerging today as potential therapeutic agents were already recognized in the past; however, the reason behind their therapeutic use was not fully understood at that time. One of these plants is Azadirachta indica A. Juss., commonly denominated as Neem tree, that has been used since very early times due to its insecticidal potential and is currently emerging as a possible therapeutic agent for various diseases (e.g. cancer) [1-4].

Azadirachtin (AZA) is a triterpenoid and one of the main bioactive compounds that can be obtained from Azadirachta indica. Nevertheless, this compound can also be isolated from other two species of Azadirachta, A. excelsa and A. siamensis [3,5]. Azadirachtin is abundantly present in mature seeds of Neem but is only detected at trace amounts in plant leaves $[3,6,7]$. The potential to use AZA as an insecticide has already been duly tested and proven. More recently, new perspectives have been advanced for AZA, namely the application in therapy, making it a versatile compound and with extreme interest for research [1,2,8-11]. In fact, AZA has been the object of intense research over the past few years aiming at exploring all its useful properties, namely those which directly benefit human health [3]. The main challenges have been to determine the complete and accurate chemical 

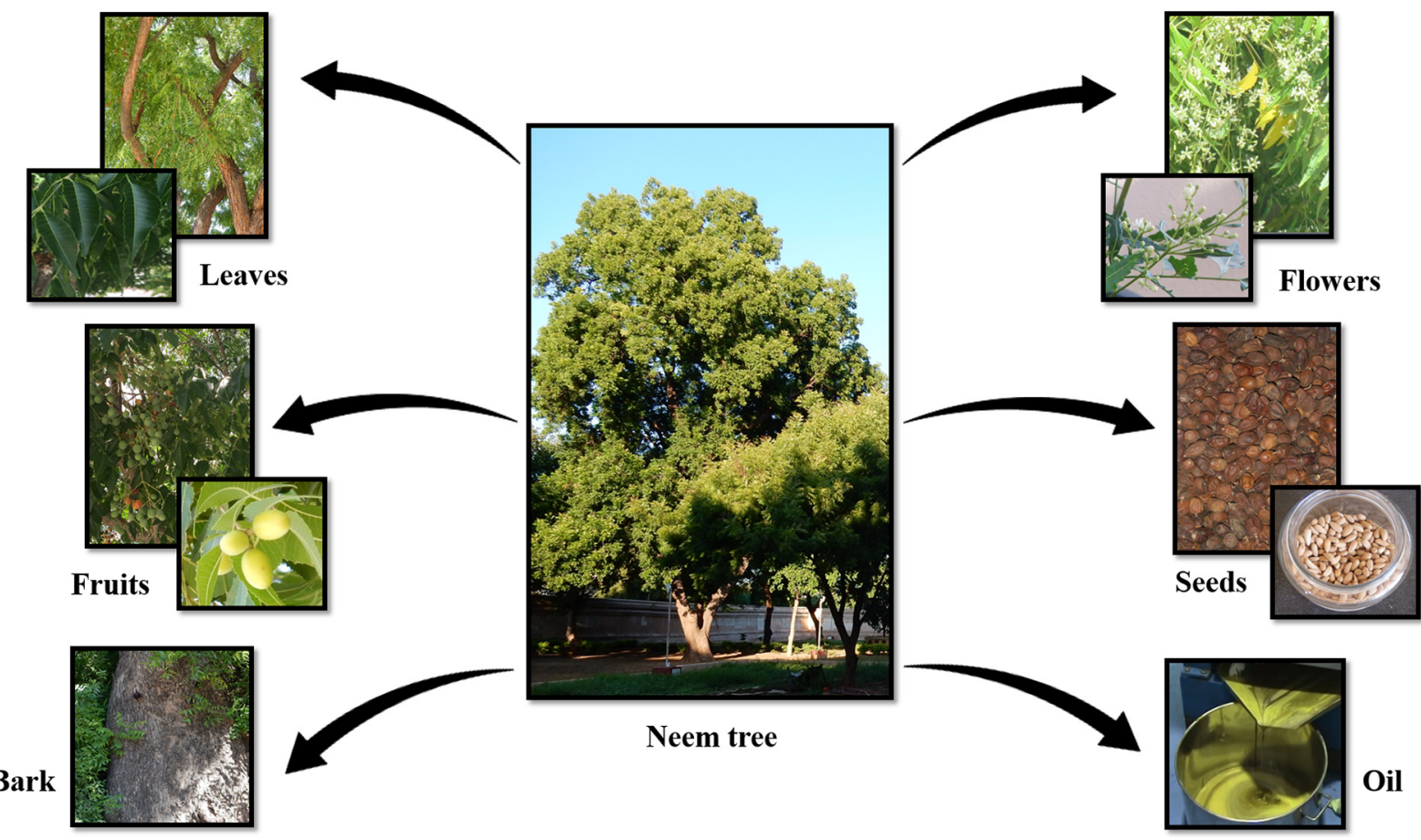

Fig. 1. The Neem plant and its components: tree, leaves, fruits, bark, flowers, seeds and oil.

structure of AZA and to synthesize artificially this compound [3,12-16].

Having this in mind, the main purpose of the present paper is to provide a state-of-the-art review about azadirachtin, namely structure, properties and applications, synthesis, extraction, identification and quantification. The assembly of these data constitute a valuable platform for the development of new therapeutic strategies based in azadirachtin or derived compounds. Moreover, researchers working on chemical analysis may obtain updated information on the methods commonly applied for extraction and determination of azadirachtin in different parts of the Azadirachta indica plant. This review is based on information retrieved in a literature search performed on the ISI Web of Knowledge search engine for papers containing the words "Azadirachta indica", "azadirachtin", "Neem", "Azadirachta indica extraction" "chromatography" or "HPLC" and published until 2018, with special emphasis in the time frame 2000-2018. A total of 91 papers were considered for this review.

\section{Azadirachta indica}

Azadirachta indica A. Juss (Fig. 1), commonly known as Neem or Margosa, is a tree belonging to the Meliaceae family and the Rutules order, used since the dawn of civilization and standing out as one of the most versatile plants worldwide [1-3,5,9,17-20]. This tree is original from India and the Southeast of Asia but nowadays its presence is disseminated around the world, especially in tropical and subtropical countries like Brazil [1-3,5,7,8,19-21]. Neem is characterized as a perennial, small to medium-sized ( 10 to $15 \mathrm{~m}$ ) and fast-growing tree $[1,3,20,21]$. Another worth mentioning feature is the ability of this tree to survive in locations with high temperatures (until $50{ }^{\circ} \mathrm{C}$ ), low annual rainfall (400-800 $\mathrm{mm}$ per year), and poor and degraded soils [3,20,22]. On the other hand, the development of the Neem tree is hindered by low temperatures, particularly below $14^{\circ} \mathrm{C}$, and frosts [23,24].

The Neem tree presents many additional features that make it a desirable target of interest for research. The possibility to obtain various active compounds from leaves and seeds thus avoiding the need for destruction of the whole plant represents an advantage [10,25]. On the other hand, the high diversity of active substances that can be extracted from the Neem tree, in opposition to plants where only one substance with activity is obtained, brings added value to this plant $[2,8,10,20,25]$. Neem presents a high proportion of water-soluble substances, which favors their easy extraction. Moreover, the majority of these compounds is biodegradable being therefore harmless to man and the environment [25].

Since early times, different parts of the Azadirachta indica plant, including leaves, bark, fruits, seeds, roots and oil (Fig. 1), have been used with multiple purposes, namely the treatment of human diseases (e.g. malaria) and pest control due to its insecticidal action [1,2,8,26]. In fact, Neem can be considered one of the most versatile plants worldwide, due to both its diverse therapeutic applications and the variety of constituents that can be obtained from the plant which, owing to their singular biochemical properties, are responsible for the different observed activities $[1,9,10]$. The myriad of therapeutic applications attributed to Neem include abortive, analgesic, anti-helminthic, antibacterial, antifungal, anti-hyperglycemic, anti-inflammatory, antiviral, antimalarial, diuretic, antipyretic, antispasmodic, antispermatogenic, anticancer, hypercholesteremic, antidiabetic, and immunomodulatory activities [1,2,10,20,27-29]. The compounds responsible for each of the referred therapeutic actions are extracted from different parts of the Neem tree [2,4,28,29]. The compounds obtained from the leaves are described as being effective in the treatment of anorexia and skin problems. The fruits are extensively used as purgative and emollients, assuming great importance in the treatment of intestinal and urinary problems, and also as anticancer agents. Anti-inflammatory and antipyretic properties are assigned to compounds obtained from leaves, seeds and oil $[8,10]$.

\section{Azadirachtin}

Azadirachtin (AZA) is the most abundant and relevant compound present in Azadirachta indica [3,6,7]. This compound can be found in various parts of the Neem tree (seeds, callus, fruits and leaves) but the concentrations are quite variable presenting values that range from $c a$. $0.25 \mu \mathrm{g} \mathrm{g}^{-1}$ in callus to $c a .48,000 \mu \mathrm{g} \mathrm{g}^{-1}$ in seeds (Table 1). Although higher contents of AZA are generally observed in seeds, those values exhibit discrepancy and have been reported in several studies [3,6,7]. This variation results from the fact that the development process of 
Table 1

Values for determination of azadirachtin content in different Neem parts.

\begin{tabular}{|c|c|c|c|}
\hline Sample & Concentration of AZA & Country of origin & Reference \\
\hline \multirow[t]{15}{*}{ Seeds } & $0.08 \%(w / w)$ & India & {$[37]$} \\
\hline & $0.0867 \%(w / w)$ & Togo West Africa & {$[81]$} \\
\hline & $752 \mathrm{ppm}$ & Germany & [93] \\
\hline & $0.56-0.30 \%(\mathrm{w} / \mathrm{w})$ & India & {$[24]$} \\
\hline & $0.21-5.13 \mathrm{mg} \mathrm{g}^{-1}$ & India & [94] \\
\hline & $0.16-0.27 \%(\mathrm{w} / \mathrm{w})$ & Brazil & {$[82]$} \\
\hline & $0.20-0.51 \%(w / w)$ & Brazil & [72] \\
\hline & $0.08-0.095 \%(\mathrm{w} / \mathrm{w})$ & India & {$[86]$} \\
\hline & $0.476-3.09 \mathrm{mg} \mathrm{g}^{-1}$ & Sudan & [95] \\
\hline & $142-9527 \mu \mathrm{g} \mathrm{g}^{-1}$ & India & {$[32]$} \\
\hline & $2.24 \mathrm{~g} \mathrm{~kg}^{-1}$ & Senegal & [96] \\
\hline & $5419.08{\mathrm{pg} \mu \mathrm{g}^{-1}}^{-1}$ & Mali & [73] \\
\hline & $5419.08 \mu \mathrm{g} \mathrm{g}^{-1}$ & India & [89] \\
\hline & $3862.9-48,521 \mu g^{-1}$ & China & [75] \\
\hline & $6.5-8.2 \mathrm{mg} \mathrm{g}^{-1}$ & China & [33] \\
\hline \multirow[t]{2}{*}{ Callus } & $0.00005 \%(\mathrm{w} / \mathrm{w})$ & Togo West Africa & [81] \\
\hline & $0.2470 \mu \mathrm{g} \mathrm{g}^{-1}$ & India & [97] \\
\hline Fruits & $0.431 \%(w / w)$ & Brazil & {$[68]$} \\
\hline \multirow[t]{3}{*}{ Leaves } & $182.42{\mathrm{pg} \mu \mathrm{g}^{-1}}^{-1}$ & Mali & [73] \\
\hline & $182.42 \mu \mathrm{g} \mathrm{g}^{-1}$ & India & [89] \\
\hline & $969.9-5419.08 \mu \mathrm{g} \mathrm{g}^{-1}$ & China & {$[75]$} \\
\hline
\end{tabular}

Neem trees is influenced by a myriad of factors, namely geographic area, climate, genetic variability, agronomic conditions, plant morphology and physiology, collection and storage of plant material [30-32]. Kaushik et al. [31] and Tomar et al. [32] analyzed trees from different regions of India and significant differences were observed in the AZA content of seeds collected in different regions. Furthermore, Kaushik et al. [31] evaluated the effect of climatic conditions in the AZA content of seeds and observed that the AZA values of samples retrieved from semi-arid regions subject to mild winters were statistically different from the values observed in hot sub-humid, hot arid and hot semi-arid with cold winter regions. On another study, Zheng et al. [33] demonstrated that the season and the ecosystem properties affected the neem seed yield and, in a less extent, the AZA content. In fact, the AZA quantity obtained in seeds was mostly influenced by precipitation, with lower values observed in the rainy season [33].

The procedure and the time of collection of plant material can also influence AZA concentration. In the case of seeds, AZA concentration is maximized when clean and healthy seeds are collected [30]. Indeed, several authors have reported that mechanical damage, insect infestation and fungal infection of seeds were associated with the extraction of reduced AZA quantities [30,34]. One the other hand, leaves should be collected when flowers have not yet flowered, and fruits only when $20 \%$ of fruit surface is yellow or $75 \%$ are physiologically ripe but still green [30]. The storage time of plant constituents also affects the AZA concentration, being observed the content of this limonoid decreases proportionally with time.

Since its isolation for the first time in 1968 and over the years, AZA has been the subject of intense research, particularly of biological, synthetic and structural studies $[7,11,16,26,35]$. The increasing interest in AZA is mainly due to the unique and particular properties of this compound, including broad spectrum of activity even when present in trace amounts, no or low toxicity to mammals, complex structure which makes its synthesis an intense challenge, and attractive biological properties. The biologically relevant activities attributed to AZA include the application as a biopesticide, given its non-toxicity to human beings, and also the use as a therapeutic agent $[2-4,7,20,36]$.

\subsection{Chemistry}

Azadirachtin (AZA, Fig. 2) is a tetranortriterpenoid of the class of limonoids that presents the chemical formula $\mathrm{C}_{35} \mathrm{H}_{44} \mathrm{O}_{16}$ and a molecular weight of $720.71 \mathrm{~g} \mathrm{~mol}^{-1}[3,6,7,24,37,38]$. AZA is closely related

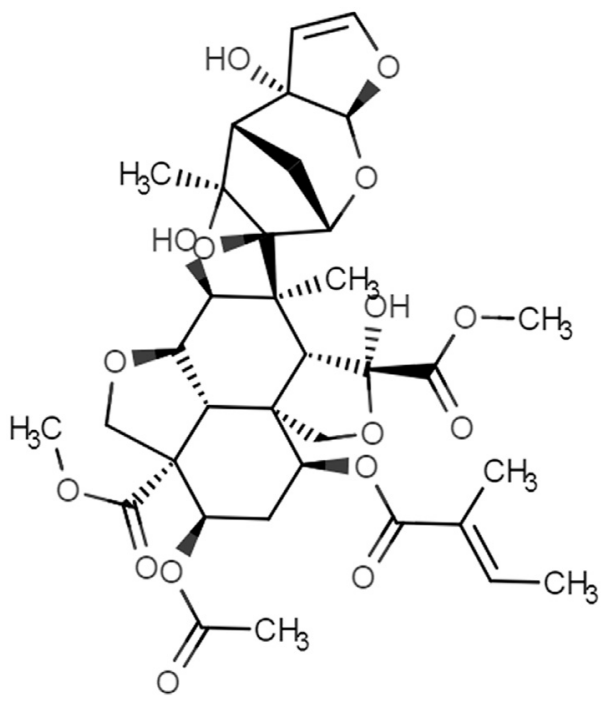

Fig. 2. Chemical structure of azadirachtin $-\mathrm{C}_{35} \mathrm{H}_{44} \mathrm{O}_{16}$.

with other compounds obtained from the seeds of Neem, namely nimbin and salanin [3,7].

The currently known chemical structure of AZA was first described in 1976 but validation of the proposed structure was required [3,12-14]. It was the application of NMR and X-ray crystallographic analysis that permitted to confirm and recognize the proposed chemical structure for AZA (Fig. 2) [3,12-14]. AZA is a highly oxidized compound that presents an extremely complex structure with a rigid conformation due to the presence of intramolecular hydrogen bonds and a large number of reactive functional groups in extremely close positions $[7,16,39]$. In addition to a rigid conformation, AZA has a particular set of oxygenated functionalities [16]. The chemical structure of AZA comprises sixteen stereogenic centers, seven of which are tetrasubstituted carbon atoms and nine are disubstituted carbon atoms $[3,16,26,39]$. Additionally, the structure of AZA comprises sixteen oxygen atoms arranged in four ester groups, one hemiacetal group and one epoxide group, two hydroxyl groups (secondary and tertiary) and one dihydrofuran group [3,16,26,39].

AZA is obtained from Neem seeds being extracted via multiple fractionations using suitable solvents. This process produces a microcrystalline powder with a molecular weight of $720.71 \mathrm{~g} \mathrm{~mol}^{-1}$, melting point at $154-158{ }^{\circ} \mathrm{C}$ and a maximum absorption in the ultraviolet region (UV) at $217 \mathrm{~nm}$ [3]. When a high purity compound is desired, the initially obtained extract has to be submitted to a purification process. Preparative HPLC is most commonly applied procedure for AZA purification resulting in a pure crystalline powder with a melting point of $160{ }^{\circ} \mathrm{C}$ [3]. The compound AZA exhibits hydrophilic character (log $P=-0.13$ ), presents moderate solubility in water and high solubility in polar organic solvents, and is photosensitive and non-volatile $[3,16]$. The stability of AZA is highly conditioned by physicochemical conditions. AZA is unstable under extreme acidic conditions, essentially due to the presence of its enol ether, under basic conditions and when submitted to high temperatures $[11,16]$. In contrast, several studies have demonstrated the basic skeleton of AZA to be remarkably stable under the influence of high temperatures, property evidenced when pyrolysis of acetic acid adduct was performed [11].

The sensitivity of AZA to acid, base and light leads to the necessity to incorporate an UV filter, such as para-aminobenzoic acid, in commercial formulations in order to reduce any risks of alterations which may jeopardize its activity [39]. Moreover, due to its particular properties, this molecule has a high propensity for rearrangements [16]. 


\subsection{Toxicity}

Azadirachtin is a biodegradable compound which potentiates its application as a pesticide and exhibits very low toxicity to mammals $[3,7,40]$. AZA acts as an insect growth regulator as it interferes with the activity of ecdysone, an insect hormone [41]. This action is a consequence of the similarity between the chemical structure of AZA and the insect hormone resulting in modifications in larval metamorphosis [41]. The $\mathrm{LD}_{50}$ is variable among different species of insects and ranges between 1 and $4 \mu \mathrm{g}$ of AZA per gram of insect [25,36].

AZA exhibits low toxicity to mammalian species with a $\mathrm{LD}_{50}$ of $5000 \mathrm{mg} \mathrm{kg}^{-1}$ in rats and an estimated safe chronic dose for human consumption of $15 \mathrm{mg} \mathrm{kg}^{-1}$ bw day ${ }^{-1}$ [42-44]. In rats, AZA causes an increase of the albumin and protein content and of blood urea and glucose levels [42]. The use of high doses of AZA during gestation has produced mild foetal skeletal variations in rats. On the other hand, the use of low doses of this compound has produced no morphological, visceral and skeletal changes in rat foetuses [45]. Furthermore, AZA is toxic to aquatic organisms, especially when high doses are administered $[46,47]$.

\subsection{Biological activities}

The biological properties of AZA have been extensively studied over the years. Among the various properties assigned to this compound, the antifeedant activity stands out as the most important, which may explain its widespread use as insecticide. However, other biological activities have been associated with this compound, such as the antimicrobial, particularly the antimalarial, and anticancer activities.

AZA has presented promising results as a chemo-preventive agent. This activity is attributed to its ability to induce anti-proliferative effects in proteins involved in the cell cycle, transduction, and apoptosis $[4,5,8,48]$. AZA induces apoptosis by a mitochondrial pathway or by engagement of death receptors $[5,48]$. The presence of AZA reduces the $\mathrm{Bcl}-2 / \mathrm{Bax}$ ratio, factor which increase is associated with the presence of tumor cells $[5,49]$. The decrease in Bcl-2/Bax ratio occurs via activation of a series of pro-apoptotic factors and inhibition of anti-apoptotic factors that are important for the control of cancer [5]. This decrease in Bcl-2/Bax ratio is accompanied by increased expression of Apaf- 1 and caspase-3, leading to a downregulation of proliferating cell nuclear antigen, which in turn leads to fragmentation and condensation indicating apoptosis $[4,5,48]$. The mechanism by which AZA exerts its anti-carcinogenic effect is equivalent to the one described for nimbolide, a compound that is also isolated from Neem [4,5,48]. In addition to the above mentioned mechanism, NF-KB has been also reported as a target in the control of tumor growth $[5,48,50]$. AZA also acts on TNFa, a pro-inflammatory cytokine playing a predominant role in signaling pathways of inflammation, apoptosis and carcinogenesis [5,50]. In this case, AZA has been reported as able to inhibit the biological activities induced by this cytokine $[5,50]$. The mechanism of inhibition is related with the obstruction of IKK activation by AZA, which is followed by the degradation of $\mathrm{IkB \alpha}[5,50]$. Other studies report that AZA may also interact with TNF receptors (TNFRs), inhibiting the binding of TNF signaling through activation of the IKK downstream, ІкB $\alpha$ degradation, nuclear translocation of $\mathrm{p} 65$ and gene transcription-dependent NF-KB $[5,50]$. In this way, by blocking the TNFa receptor, AZA inhibits the activation of NF-KB and is thus able to perform an effective control of inflammation $[5,50]$.

In addition to its anti-carcinogenic effect, azadirachtin has been extensively associated with antimalarial activity $[1,8,20,27]$. This antimicrobial property is attributed to the capacity of AZA to block the formation of microtubules in the development stages of the parasite responsible for malaria pathology [1,3,20,51].

In spite of the remarkable therapeutic applications, AZA and other compounds isolated from Neem have been mainly used as insecticides, since their discovery [3]. Over the years, the investigation on AZA pesticide activity has increased dramatically [52]. AZA presents a set of characteristics that permit to consider it an excellent insecticide, particularly a biopesticide. Among such characteristics, the broad spectrum of activity stands out, as well as the absence of toxicity to man and the environment $[3,7,40]$. The effect of AZA on insects is variable and include modifications in the ingestion or growth processes [3,7]. Other effects have been attributed to the presence of AZA, in particular, the repellence of adult insects, which leads to the decrease of eggs, thus preventing insects proliferation [3,7].

The recognition of structure-activity relationships is crucial to clearly understand the molecular requirements behind the occurrence of the bioactivities of AZA [39]. In the case of antifeeedant activity, the structure-bioactivity relationship has been studied over the years by several authors, who concluded that AZA molecular modifications and/ or reactions did produce different responses in the observed activities. One of the described reactions consists of a hydrogenation in the olefinic bond of the AZA dihydrofuran ring, thus producing a tetrahydroderivative, more stable in acidic and photo-oxidative conditions than AZA, and with significant antifeedant activity [39,53,54]. Moreover, Rembold et al. $[53,54]$ observed that the presence of this derivative did not influence AZA inhibiting activity of the metamorphosis of Epilachnu variuestis and Locusta migratoriu. In other study conducted by Morgan [55] the above mentioned derivative, as well as the deacetylated one, were reported as potent antifeedants against desert locusts. In addition, the same study revealed that the occurrence of acetylation and/or trimethylsilylation of AZA hydroxyl groups originated compounds with reduced antifeedant effect on $S$. gregaria. In order to achieve its maximum activity as an insecticide, the AZA molecule must present both a lipophilic and a hydrophilic side containing hydroxyl groups $[39,56]$. On the other hand, the presence of carbon-carbon double bonds and acetyl groups are not necessary for this type of biological activity $[39,56]$.

\subsection{Biosynthesis and artificial synthesis}

Azadirachtin (AZA) is produced through a rather complex biosynthetic pathway in which the steroid tirucallol is identified as the main precursor [36,39,40,57]. Indeed, tirucallol is the main precursor of the majority of secondary metabolites of the Neem tree. Tirucallol consists in two units of farnesyl diphosphate, in order to form C30 triterpene that subsequently loses three methyl groups and originates a C27 steroid [57]. The biosynthesis of AZA (Fig. 3) probably results from the degradation of tirucallol that gives raise to butyrospermol through allylic isomerization $[39,57,58]$. Subsequently, a series of oxidation reactions occurs and, after rearrangement through a shift of WagnerMeerwein 1,2 methyl, apotirucallol is formed [39,57,58]. The limonoids, in particular the tetranortriterpenoids such as azadirachtin, are formed by cleavage of the four carbon atoms of the side chain terminal of apotirucallol $[57,58]$. The remaining atoms forming the side chain of this intermediary originate a furan ring through cyclization. This molecule is then oxidized and gives raise to the formation of azadirone and azadiradione $[57,58]$. The third ring of azadirone and azadiradione is further cleaved and oxidation occurs leading to the formation of C-secolimonoids, namely salannin. Finally, salannin is oxidized and cyclized and gives raise to the formation of AZA $[39,57,58]$.

Chemical synthesis of azadirachtin in the laboratory is a complex and difficult process $[3,15,16]$. This is mainly due to AZA chemical particularities, especially the sensitivity to alkaline media, the presence of hydrogen bonds and a complex internal structure $[3,11,16]$. Due to these constraints, the synthesis of AZA took about 20 years to be completed and only in 2008 it was possible to effectively conclude the process of artificial synthesis of AZA [3,11,16,26]. Several authors have proposed a mechanism of synthesis in which AZA is obtained from a parent compound named vepaol, which was previously formed also by chemical synthesis [11,26]. Nevertheless, other synthesis approaches have been proposed, including a method of synthetic 


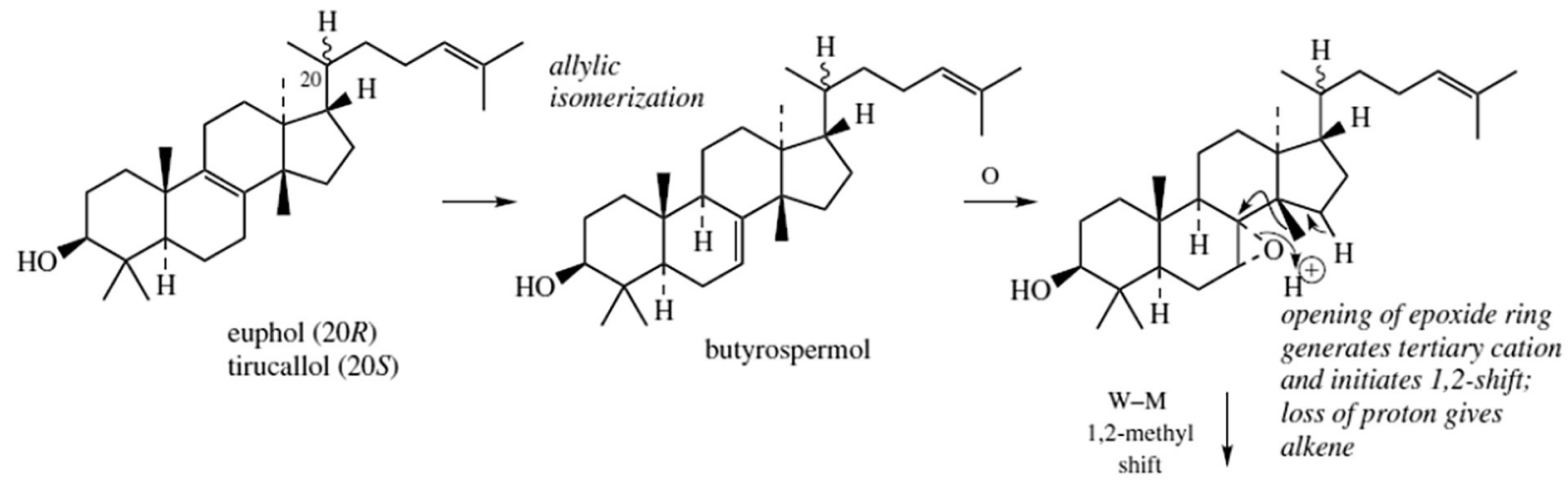

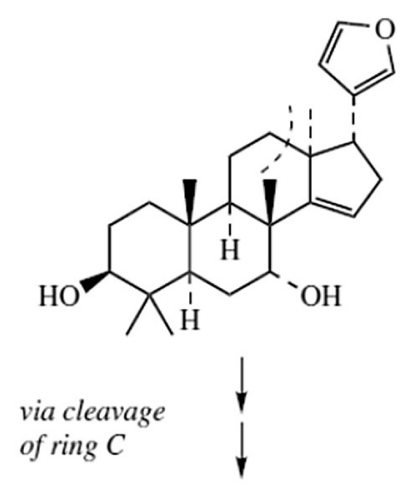<smiles>CC(C)=CCC(C)C</smiles>

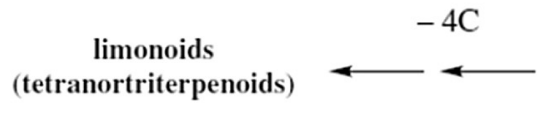

cleavage of 4 carbons from side-chain and formation of furan ring as indicated

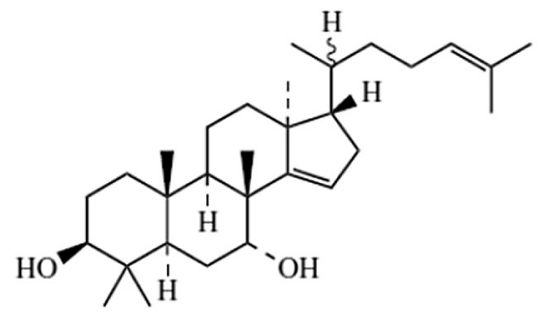

apoeuphol (20R) apotirucallol (20S)

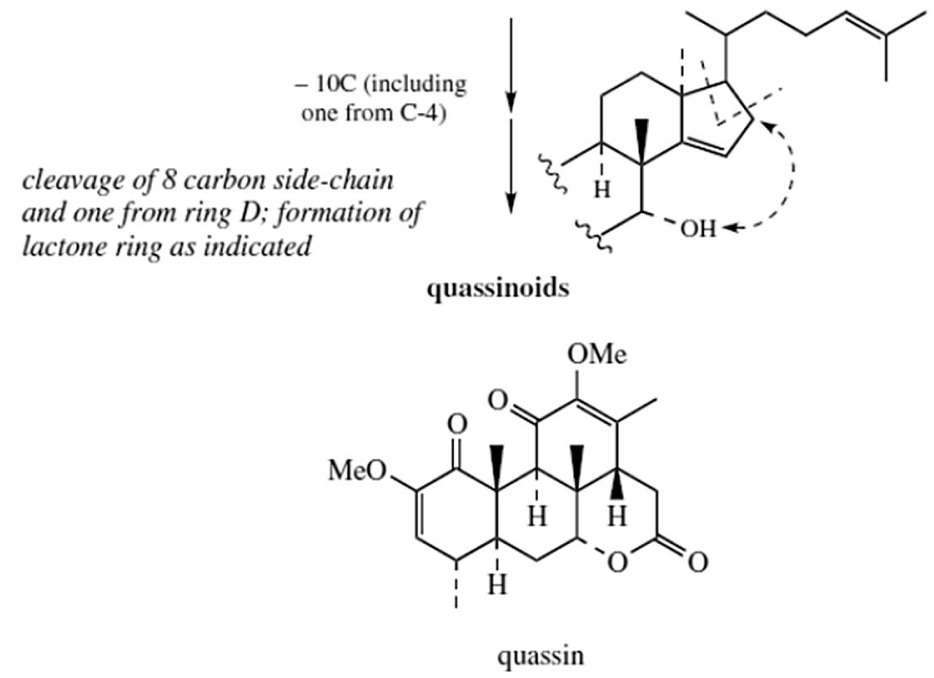

Fig. 3. Biosynthetic pathway leading to the formation of azadirachtin [57]. Reproduced with kind permission from John Wiley \& Sons, Inc.

retrotransformation, in which the final formed product AZA can be converted back to its precursors [3]. Thus, after a long period of 20 years of research, the synthesis of AZA at the laboratory level was possible, being performed in 71 steps, with a yield of $0.00015 \%[3,15]$. This long process of research brought added value to the field such as the possibility to artificially obtain five other products that occur naturally and are closely related with AZA [3].

In the AZA synthesis pathway proposed by Ley and his collaborators, the first step consists in producing a suitable decalin fragment obtained by coupling two quaternary carbon centers, in order to form the extremely hindered bond between C8 and C14 [16,35,59,60]. The synthesis of this decalin fragment represents one of the biggest challenges in the artificial synthesis of AZA, because this process comprises ten contiguous stereocenters and a complex oxygenation [35,59]. Furthermore, the formation of this decalin fragment is only possible after the completion of 31 steps. In the next stage, a bond between C8 and C14 is formed $[16,35,59,60]$. First, an $O$-alkylation reaction occurs to connect the decalin ketone and the propargylic mesylate fragments. After this reaction, the C8-C14 bond is formed by a Claisen rearrangement. Subsequently, the allene previously formed enables another carbon-carbon bond formation reaction $[16,35,59,60]$. This sequence of reactions involves the cyclisation of the 5-exo-radical to produce a bicyclic system. Finally, additional reactions and processes take place to complete the synthesis of AZA and obtain the final product $[16,35,59,60]$.

\subsection{Extraction}

As mentioned before, azadirachtin (AZA) is mainly extracted from the seeds of Neem, that constitute the plant portion presenting higher content of this compound [3,6,7].

The methods for extraction of AZA from the Neem tree are diverse and the selection of the appropriate extraction technique does not seem to be influenced by the part of the plant from which the target analyte will be isolated (Table 2). In fact, the same extraction methods have been applied to the separation of AZA from different portions of the Neem plant. Solid-liquid extraction is commonly used to treat both seeds, leaves and bark $[38,61,62]$. Other techniques are also frequently 
Table 2

Summary of extraction methods used for the isolation of azadirachtin from Neem tree.

\begin{tabular}{|c|c|c|c|c|c|}
\hline Sample & Extraction method & Extraction time & Solvents & Identification method & Reference \\
\hline \multirow[t]{2}{*}{ Seeds } & Soxhlet extraction & $24-72 \mathrm{~h}$ & Methanol & HPLC-UV & [37] \\
\hline & Schroeder and Nakanishi method & $30 \mathrm{~min}$ & Ethanol & & \\
\hline Seeds & Solid-phase extraction & n.a. & n.a. & SFC & [67] \\
\hline \multirow[t]{3}{*}{ Dry seeds kernels } & Solid-liquid extraction & $24 \mathrm{~h}$ & Methanol & HPLC-UV & {$[38]$} \\
\hline & Cold extraction & n.a. & Ethanol & HPTLC & \\
\hline & Extraction & $\sim 2 \mathrm{~h}$ and $10 \mathrm{~min}$ & & GC & \\
\hline \multirow[t]{3}{*}{ Leaves, fruits, flowers and stem bark } & Maceration & $7 \mathrm{~d}$ & Methanol & n.a. & {$[66]$} \\
\hline & Baking & $6-8 \mathrm{~h}$ & Hexane & & \\
\hline & & & Ethanol & & \\
\hline \multirow[t]{4}{*}{ Leaves } & Percolation, decoction, freeze drying or spray & $6 \mathrm{~h}$ & Water & TLC & {$[65]$} \\
\hline & drying & & Methanol & & \\
\hline & Maceration & $7 \mathrm{~d}$ & & & \\
\hline & Soxhlet extraction & n.a. & & & \\
\hline \multirow[t]{3}{*}{ Leaves } & Cold extraction & $48 \mathrm{~h}$ & Petroleum ether & n.a. & [64] \\
\hline & Reflux extraction & $15 \mathrm{~h}$ & Hexane & & \\
\hline & Soxhlet extraction & $48 \mathrm{~h}$ & & & \\
\hline Leaves & Solid-liquid extraction & n.a. & Methanol & n.a. & {$[62]$} \\
\hline \multirow[t]{3}{*}{ Bark } & Solid-liquid extraction & n.a. & Absolute ethanol & Spectrophotometric method & {$[61]$} \\
\hline & Shaking & & Methanol & & \\
\hline & Reflux & & & & \\
\hline Oil & Solvent precipitation & n.a. & Hexane & HPLC-UV & {$[85]$} \\
\hline \multirow[t]{2}{*}{ Fruits } & Percolation & n.a. & Hexane & HPLC-UV & {$[22]$} \\
\hline & & & Methanol & TLC & {$[75]$} \\
\hline \multirow[t]{3}{*}{ Seeds } & Extraction with different solvents & n.a. & Water & HPLC-UV & [73] \\
\hline & & & Organic solvents & LC-MS/MS & \\
\hline & & & Aqueous salt solutions & & \\
\hline \multirow[t]{2}{*}{ Seeds } & Pressurized Liquid Extraction & n.a. & n.a. & HPLC-UV & [63] \\
\hline & Maceration & $3 \mathrm{~d}$ & Methanol & & \\
\hline \multirow[t]{3}{*}{ Seeds } & Cold-pressing & n.a. & Hexane & HPLC-UV & [74] \\
\hline & Soxhlet extraction & $4 \mathrm{~h}$ & & & \\
\hline & Supercritical $\mathrm{CO}_{2}$ extraction & $4 \mathrm{~h}$ & & & \\
\hline Fruits & Ultrasound-assisted extraction & $30 \mathrm{~min}$ & Ethanol & HPLC-UV & {$[68]$} \\
\hline Seeds and leaves & Solid-phase extraction & n.a. & Methanol & LC-MS & {$[75]$} \\
\hline
\end{tabular}

GC, Gas Chromatography; HPLC, High-Performance Liquid Chromatography; HPTLC, High-Performance Thin Layer Chromatography; LC, Liquid Chromatography; MS, Mass Spectrometry detection; MS/MS, Tandem Mass Spectrometry detection; n.a., not available; SFC, Supercritical Fluid Chromatography; TLC, Thin Layer Chromatography; UV, Ultraviolet detection.

applied such as maceration or temperature based extraction with solvents [38,63-65]. The majority of processes used for AZA isolation are time-consuming with extraction periods ranging from minutes to days. Maceration is the longer process requiring approximately 7 days for compound removal $[37,38,61-67]$. On the contrary, the methods involving shorter times for extraction, i.e. $30 \mathrm{~min}$, are the Schroeder and Nakanishi technique and ultrasound-assisted extraction [37,38,61-68]. The procedures for extraction of AZA generally involve the use of multiple solvents in order to ensure that only the target compound is extracted and to maximize recovery percentages $[7,69]$. Recent studies have reported different percentages of AZA recovery according to the solvent used thus indicating the utmost importance of adequate solvent selection. Another relevant factor that influences the selection of the extraction solvent is the intended purity grade [7,69]. Due to the moderate solubility of AZA in water, the aqueous extraction of this triterpenoid often results in lower recovery percentages and requires large amounts of water. On the opposite, due to the high solubility of limonoids in organic solvents, the removal of AZA from the different plant parts with alcohol solvents is very efficient, reaching extraction yields 50 times higher than water extraction [41]. Indeed, the majority of published studies report the use of alcohols, namely methanol an ethanol to perform the extraction of AZA from the Neem tree parts (Table 2). Additionally, hexane is also used to extract the oil from Neem and to remove non-polar compounds from AZA extracts [41].

After isolation of the active compound from the plant portions, there is generally the need to clean-up the extract in order to increase the purity of the target substance $[3,7,69]$. Several techniques are available for the purification of plant extracts, being preparative high-performance liquid chromatography (HPLC) the most commonly applied. The compound resulting from this procedure may be further purified by other techniques such as high-speed countercurrent chromatography, medium-pressure liquid chromatography and microwave-assisted extraction [7,22,25,69-71].

In order to verify if the target compound has been efficiently extracted and purified, identification assays are often performed. In the case of AZA, different methods have been reported to perform its identification, including HPLC $[22,37,38,63,68,72-75]$, spectrophotometry [61], thin-layer chromatography (TLC) [22,38,65,72], and gas chromatography (GC) [38]. Furthermore, HPLC has been frequently associated with UV detection as a standard technique for identification of AZA [22,37,38,63,68,72-75].

\subsection{Methods of analysis}

Several methods have been described for the identification and quantification of azadirachtin in plant extracts. Comprehensive methods, namely liquid chromatography coupled to different detection systems, are preferably applied for AZA determination [24,40]. Nevertheless, other analytical approaches can be also employed such as colorimetric based techniques [7,71,76]. Dai et al. [76] developed a colorimetric method based on the addition of an acidified vanillin solution in methanol that permitted to detect the presence of AZA and other limonoids in Neem seed kernel extracts but did not allow the individual quantification of each target compound. Other authors proposed an immunoassay for the determination of AZA, particularly the quantitative enzyme-linked immunosorbent assay (ELISA) [77].

In what concerns chromatographic techniques, the majority of studies report the application of High-performance Liquid Chromatography (HPLC) for the analysis of AZA [7]. However, other chromatography-based techniques can be also employed and have been 


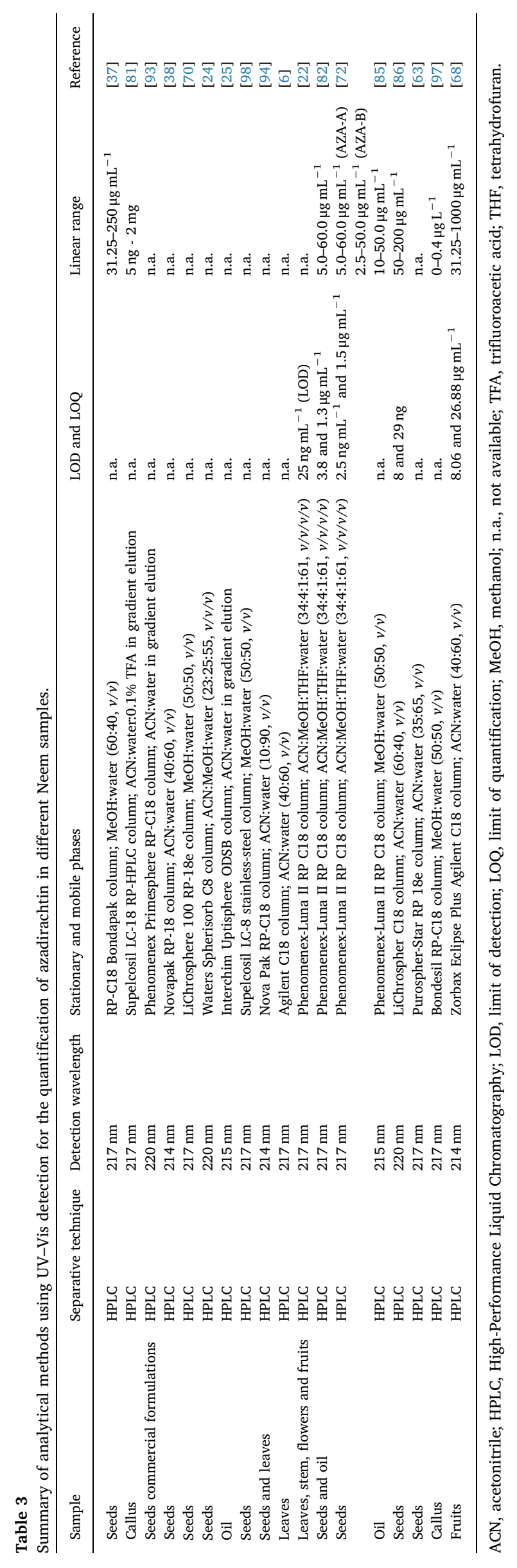

developed for AZA detection, namely Gas Chromatography (GC) and Thin-Layer Chromatography (TLC) [3,6,38]. Ermel et al. [78] used TLC coupled with fluorescence for the determination of AZA recovered from seeds of Azadirachta indica. Some studies [38,40,52,79] reported the use of Supercritical Fluid Chromatography (SFC) to perform both qualitative and quantitative analysis of AZA. Due to the non-volatility and medium polarity of AZA, reversed-phase liquid chromatography is often the method of choice to perform the separation, identification and quantification of this substance [3]. This fact is depicted by the high number of published papers reporting the use of reversed-phase HPLC for AZA analysis in plant extracts (Table 3). Mobile phase often comprises a mixture of water and an organic solvent, particularly acetonitrile or methanol (Table 3). Many studies have described the use of a mixture containing acetonitrile and water in the proportion 40:60 $(\mathrm{v} / \mathrm{v})$ for the determination of AZA [6,25,68,76,80-84]. The adjustment of mobile phase $\mathrm{pH}$ is generally not required as the AZA molecule presents a single form, i.e. the neutral form, for $\mathrm{pH}$ values up to 8 (Fig. S1). The use of water-organic solvent mixtures permits to guarantee that the $\mathrm{pH}$ of the mobile phase is within the range at which the neutral form of AZA prevails. For $\mathrm{pH}$ values above 10 other species prevail, namely negatively charged species (Fig. S1). Separation at these higher $\mathrm{pH}$ values is not recommended to prevent damaging the chromatographic column.

Chromatographic separation of AZA has been performed in isocratic and also in gradient mode. The selection of isocratic elution was generally associated with a faster analysis and lower retention times being therefore the preferred mode of analysis in most studies $[6,22,24,37,38,73,74,76,82,85,86]$. On the other hand, elution in gradient mode generally resulted in longer chromatographic runs limiting its application $[25,81,87,88]$. Barrek et al. [25] used a column with the dimensions of $250 \times 4.6 \mathrm{~mm}$ and elution in gradient mode resulting in a retention time of $21.3 \mathrm{~min}$ for AZA. On the other hand, Dai et al. [76] used a column with the same dimensions but elution was performed in isocratic mode leading to a lower retention time for AZA (10.2 min) and, thus, faster analysis. Furthermore, Kaushik and collaborators [38] performed chromatographic separation using a column with smaller dimensions $(150 \times 3.9 \mathrm{~mm})$ and isocratic elution and were able to separate AZA within 3 min.

Different detection systems can be coupled to chromatographic separation being UV-Vis spectrophotometry commonly employed due to availability of this type of detector in laboratories worldwide. AZA presents maximum absorption at low wavelength values $(\leq 220 \mathrm{~nm})$ where a large number of other compounds, including solvents, also absorb and may hamper AZA determination [3]. In fact, the AZA molecule does not possess strong UV absorbing chromophores. Nevertheless, UV-Vis detection after HPLC separation has been performed at wavelength values ranging between 214 and $220 \mathrm{~nm}$ (Table 3) and the majority of studies report the detection of AZA at $217 \mathrm{~nm}$ as the wavelength permitting to maximize sensitivity $[6,22,37,40,70,80,82]$.

Liquid chromatography with UV-Vis detection has been applied to detect and quantify AZA in extracts from different parts of the Neem plant. The majority of studies described the analysis of sample extracts obtained from seeds and leaves, particularly hydro-alcoholic extracts [22,24,37,38,40,70,72,76,80-82]. On the contrary, Neem oil seems to be the least studied plant portion and, consequently, the accurate amount of azadirachtin present in this sample is not yet fully known [25]. Other studies have focused on the analysis of AZA in commercial formulations contain Neem oil [83,84].

In recent years, liquid chromatographic methods coupled to mass spectrometry and also tandem mass spectrometry detection (LC-MS and LC-MS/MS, respectively) have gone through major developments and are increasingly becoming the most commonly employed analytical strategies for AZA detection and quantification in real matrices $[22,25,72,73,75,81,82,89]$. The combination of both techniques offers the possibility of taking advantage of chromatography as a separation technique and MS as an unequivocal identification and quantification 
tool. Indeed, LC-MS and LC-MS/MS techniques enable the screening, confirmation and quantification of multiple components within a single analysis. Moreover, the use of MS as detection system permits the achievement of low limits of detection. LC-MS analysis of plant extracts targeting the quantification of AZA has been generally conducted using electrospray ionization (ESI) and, in some cases, using atmospheric pressure chemical ionization (APCI). Negative ionization mode was used in the majority of the published studies (Table 4). AZA seems to be easily ionized into a negatively charged ion $[\mathrm{M}-\mathrm{H}]^{-}$at $m / z 719$ that is subsequently used as precursor ion for the selected reaction monitoring (SRM) of specific mass transitions. In negative ionization mode, product ions resulting from the loss of a molecule of methanol $(\mathrm{m} / \mathrm{z} 687)$ or a molecule of acetic acid $(m / z 659)$ have been observed [72,82]. Moreover, in positive ionization mode, the formation of adduct ions with sodium $(\mathrm{m} / \mathrm{z} 743)$ or potassium $(\mathrm{m} / \mathrm{z} 759)$ and ions resulting from the subsequent loss of water molecules $(m / z 703$ and $m / z 685)$ has been often reported [81,89].

The limits of detection (LOD) attained by chromatography techniques with mass spectrometry detection reached values in the $\mathrm{ng} \mathrm{mL}^{-1}$ to low $\mu \mathrm{g} \mathrm{mL}^{-1}$ levels (Table 4). When UV-Vis detection was used, higher LODs in the $\mu \mathrm{g} \mathrm{mL}^{-1}$ level were obtained, with values ranging in most cases from 1.3 to $27 \mu \mathrm{gL}^{-1}$ (Table 4).

\section{Other limonoids}

Limonoids are the compounds most commonly found in the Neem tree $[3,85]$. The literature describes a huge diversity of limonoids but the most abundant are azadirachtin A (azadirachtin), salanin, nimbin, azadirachtin B (3-tigloylazadirachtol) and azadirachtin D (1-acetyl-3tigloyl-11-hydroxymeliacarpin) [3,29,85]. Rembold et al. [54,90] introduced the designations azadirachtin $\mathrm{A}, \mathrm{B}, \mathrm{C}$ and $\mathrm{D}$ and considered these four compounds as isomers of AZA [3,22,72]. However, subsequent studies describing in detail the chemical structure of these four compounds concluded that those designations and the identification as isomers had been incorrectly assigned. In fact, these compounds did not belong to the same chemical group and thus could not be considered isomers [3,22,72]. Azadirachtin A (AZA-A) and B (AZA-B) are often analyzed simultaneously due to their similarity in structure and high abundance in the Neem plant $[3,22,72]$. The limonoid AZA-A is identical to azadirachtin and therefore is usually designated by the original name azadirachtin $[3,22,72,83,85,91]$. The accurate chemical structure of AZA-B was firstly described by Kraus et al. [92] that designated this compound as 3-tigloylazadirachtol, name that prevails until today. Nevertheless, the designation AZA-B is accepted and commonly used $[3,22,72,83,85]$.

\section{Conclusions}

The evolution of the modern society demands to search for new therapeutic solutions to new and also old pathologies. These therapeutic solutions may be provided by natural and underexploited sources featuring high potentialities such as plants. Azadirachtin and Neem are emerging as a good example of this.

The intense years of research on the Azadirachta indica A. Juss (Neem) tree, and in particular on its main bioactive compound azadirachtin, suggest that this plant is indeed a source of singular substances whose features can be used to benefit human life. At the beginning, only the activity of AZA as a biopesticide was recognized. Studies performed later evidenced interesting therapeutic applications for AZA, namely anticancer and antimicrobial capacities. Nevertheless, the knowledge on the bioactivities of Neem and AZA should be further investigated in order to take the best advantage of the potential benefits of these compounds.

On the other hand, the identification and quantification of the active compounds present in the different parts of the Neem tree are essential for a better recognition of their properties and potentialities. The 
comparison of the different studies describing methods for analytical determination of AZA in plant matrices suggests there is not a specific extraction method to each part of the Neem tree. Nevertheless, it is possible to identify the methods most frequently applied for extraction, purification and determination of AZA which are, respectively, solidliquid extraction, preparative chromatography and HPLC.

\section{Acknowledgements}

This work received financial support from the European Union (FEDER funds) and National Funds (FCT/MEC, Fundação para a Ciência e a Tecnologia and Ministério da Educação e Ciência) under the Partnership Agreement PT2020 UID/QUI/50006/2013 - POCI/01/ 0145/FEDER/007265. S. R. Fernandes and L. Barreiros thank FCT and POCH (Programa Operacional Capital Humano) for their grants (SFRH/ $\mathrm{BD} / 130948 / 2017$ and SFRH/BPD/89668/2012). The authors gratefully acknowledge Inês Grego and Verónica Ferreira for valuable help in tables preparation.

\section{References}

[1] K. Biswas, I. Chattopadhyay, R.K. Banerjee, U. Bandyopadhyay, Biological activities and medicinal properties of neem (Azadirachta indica), Curr. Sci. 82 (11) (2002) $1336-1345$

[2] G. Brahmachari, Neem - an omnipotent plant: a retrospection, ChemBioChem 5 (4) (2004) 409-421.

[3] E.D. Morgan, Azadirachtin, a scientific gold mine, Bioorg. Med. Chem. 17 (12) (2009) 4096-4105.

[4] R. Paul, M. Prasad, N.K. Sah, Anticancer biology of Azadirachta indica L (neem): a mini review, Cancer Biol. Ther. 12 (6) (2011) 467-476.

[5] U. Bandyopadhyay, S. Bindu, Beneficial effect of neem on human health, in: A.A. Farooqui, T. Farooqui (Eds.), Phytochemicals and Human Health, Nova Science Publishers, Inc, 2011, pp. 187-218.

[6] P.D. Alves, M.G.L. Brandao, E.A. Nunan, C.D. Vianna-Soares, Chromatographic evaluation and antimicrobial activity of neem (Azadirachta indica A. Juss., Meliaceae) leaves hydroalcoholic extracts, Rev. Bras. Farmacogn.-Braz. J. Pharmacogn. 19 (2b) (2009) 510-515.

[7] G. Prakash, S. Bhojwani, A. Srivastava, Production of azadirachtin from plant tissue culture: state of the art and future prospects, Biotechnol. Bioprocess Eng. 7 (4) (2002) 185-193.

[8] P.S. Kumar, D. Mishra, G. Ghosh, C. Panda, Biological action and medicinal properties of various constituent of Azadirachta indica (Meliaceae) an overview, Ann. Biol. Res. 1 (3) (2010) 24-34.

[9] I. Chattopadhyay, B. Nandi, R. Chatterjee, K. Biswas, U. Bandyopadhyay, R.K. Banerjee, Mechanism of antiulcer effect of neem (Azadirachta indica) leaf extract: effect on $\mathrm{H}+-\mathrm{K}+$-ATPase, oxidative damage and apoptosis, Inflammopharmacology 12 (2) (2004) 153-176.

[10] P. Maity, K. Biswas, I. Chattopadhyay, R.K. Banerjee, U. Bandyopadhyay, The use of neem for controlling gastric hyperacidity and ulcer, Phytother. Res. 23 (6) (2009) 747-755.

[11] G.E. Veitch, A. Boyer, S.V. Ley, The azadirachtin story, Angew. Chem.-Int. Edit. 47 (49) (2008) 9402-9429.

[12] J.N. Bilton, H.B. Broughton, P.S. Jones, S.V. Ley, Z. Lidert, E.D. Morgan, H.S. Rzepa, R.N. Sheppard, A.M.Z. Slawin, D.J. Williams, An X-ray crystallographic, mass spectroscopic, and NMR-study of the limonoid insect antifeedant azadirachtin and related derivatives, Tetrahedron 43 (12) (1987) 2805-2815.

[13] S.V. Ley, H. Lovell, D.J. Williams, Chemistry of insect antifeedants from Azadirachta indica, part 14: absolute configuration of azadirachtin, J. Chem. Soc. Chem. Commun. (18) (1992) 1304-1306.

[14] P.R. Zanno, I. Miura, K. Nakanishi, D.L. Elder, Structure of the insect phagorepellent azadirachtin. Application of PRFT/CWD [partially relaxed Fourier transform/continuous wave decoupling] carbon-13 nuclear magnetic resonance, J. Am. Chem. Soc. 97 (7) (1975) 1975-1977.

[15] J. Jauch, Total synthesis of azadirachtin-finally completed after 22 years, Angew. Chem.-Int. Edit. 47 (1) (2008) 34-37.

[16] G.E. Veitch, E. Beckmann, B.J. Burke, A. Boyer, S.L. Maslen, S.V. Ley, Synthesis of azadirachtin: a long but successful journey, Angew. Chem.-Int. Edit. 46 (40) (2007) 7629-7632.

[17] J.M. Dai, V.A. Yaylayan, G.S.V. Raghavan, J.R. Pare, Extraction and colorimetric determination of azadirachtin-related limonoids in neem seed kernel, J. Agric. Food
Chem. 47 (9) (1999) 3738-3742.

[18] K.M. Koriem, Review on pharmacological and toxicologyical effects of oleum azadirachti oil, Asian Pac. J. Trop. Med. 3 (10) (2013) 834-840.

[19] J.S.S. Pinto, F.M. Lanças, Hidrólise do óleo de Azadirachta indica em água subcrítica e determinação da composição dos triacilglicerídeos e ácidos graxos por cromatografia gasosa de alta resolução a alta temperatura e cromatografia gasosa de alta resolução acoplada à espectrometria de massas, Quím. Nova 33 (2010) 394-397.

[20] I. Hashmat, H. Azad, A. Ahmed, Neem (Azadirachta indica A. Juss) - a nature's drugstore: an overview, Int. Res. J. Biol. Sci. 1 (6) (2012) 76-79.

[21] J.B. Paes, A.D. Souza, C.R. Lima, P.N. Medeiros Neto, Eficiência dos óleos de nim (Azadirachta indica) e de mamona (Ricinus communis) na protecão da madeira de sumaúma (Ceiba pentandra) contra cupins xilófagos em ensaio de preferência alimentar, Rev. Árvore 35 (2011) 751-758.

[22] M.R. Forim, V.E. Cornelio, M.F. da Silva, E. Rodrigues-Filho, J.B. Fernandes, P.C. Vieira, S.S. Matinez, M.P. Napolitano, R.A. Yost, Chemical characterization of Azadirachta indica grafted on Melia azedarach and analyses of azadirachtin by HPLC-MS-MS (SRM) and meliatoxins by MALDI-MS, Phytochem. Anal. 21 (4) (2010) 363-373.

[23] H. Schmutterer, Properties and potential of natural pesticides from the neem tree, Azadirachta indica, Annu. Rev. Entomol. 35 (1990) 271-297.

[24] O.P. Sidhu, V. Kumar, H.M. Behl, Variability in neem (Azadirachta indica) with respect to azadirachtin content, J. Agric. Food Chem. 51 (4) (2003) 910-915.

[25] S. Barrek, O. Paisse, M.-F. Grenier-Loustalot, Analysis of neem oils by LC-MS and degradation kinetics of azadirachtin-a in a controlled environment, Anal. Bioanal. Chem. 378 (3) (2004) 753-763.

[26] G.E. Veitch, A. Pinto, A. Boyer, E. Beckmann, J.C. Anderson, S.V. Ley, Synthesis of natural products from the indian neem tree Azadirachta indica, Org. Lett. 10 (4) (2008) 569-572.

[27] S. Tapanelli, G. Chianese, L. Lucantoni, R.S. Yerbanga, A. Habluetzel, O. Taglialatela-Scafati, Transmission blocking effects of neem (Azadirachta indica) seed kernel limonoids on Plasmodium berghei early sporogonic development, Fitoterapia 114 (2016) 122-126.

[28] Y.Q. Zhang, J.A. Xu, Z.Q. Yin, R.Y. Jia, Y. Lu, F. Yang, Y.H. Du, P. Zou, C. Lv, T.X. Hu, S.L. Liu, G. Shu, G. Yi, Isolation and identification of the antibacterial active compound from petroleum ether extract of neem oil, Fitoterapia 81 (7) (2010) 747-750.

[29] S.I. Kurimoto, Y. Takaishi, F.A. Ahmed, Y. Kashiwada, Triterpenoids from the fruits of Azadirachta indica (Meliaceae), Fitoterapia 92 (2014) 200-205.

[30] R.T. Gahukar, Factors affecting content and bioefficacy of neem (Azadirachta indica A. Juss.) phytochemicals used in agricultural pest control: a review, Crop Prot. 62 (2014) 93-99.

[31] N. Kaushik, B.G. Singh, U.K. Tomar, S.N. Naik, S. Vir, S.S. Bisla, K.K. Sharma, S.K. Banerjee, P. Thakkar, Regional and habitat variability in azadirachtin content of Indian neem (Azadirachta indica A. Jusieu), Curr. Sci. 92 (10) (2007) 1400-1406.

[32] U.K. Tomar, G. Singh, N. Kaushik, Screening Azadirachta indica tree for enhancing azadirachtin and oil contents in dry areas of Gujarat, India, J. For. Res. 22 (2) (2011) 217-224.

[33] Y.X. Zheng, J.C. Wu, Y.Q. Wang, X.M. Peng, Y.P. Zhang, Seed yield and azadirachtin content of Azadirachta indica in four ecosystems of southwest China, Ind. Crop. Prod. 122 (2018) 23-27.

[34] K. Tanuja, G. Kavitha, R. Karuna, R.B. Sashidhar, Substrate suitability of neem seed kernel for the growth and elaboration of aflatoxins by Aspergillus parasiticus (NRRL- 2999), Indian J. Nat. Prod. Resour. 3 (2012) 395-406.

[35] S.V. Ley, A. Abad-Somovilla, J.C. Anderson, C. Ayats, R. Bänteli, E. Beckmann, A. Boyer, M.G. Brasca, A. Brice, H.B. Broughton, B.J. Burke, E. Cleator, D. Craig, A.A. Denholm, R.M. Denton, T. Durand-Reville, L.B. Gobbi, M. Göbel, B.L. Gray, R.B. Grossmann, C.E. Gutteridge, N. Hahn, S.L. Harding, D.C. Jennens, L. Jennens, P.J. Lovell, H.J. Lovell, M.L. de la Puente, H.C. Kolb, W.-J. Koot, S.L. Maslen, C.F. McCusker, A. Mattes, A.R. Pape, A. Pinto, D. Santafianos, J.S. Scott, S.C. Smith, A.Q. Somers, C.D. Spilling, F. Stelzer, P.L. Toogood, R.M. Turner, G.E. Veitch, A. Wood, C. Zumbrunn, The synthesis of azadirachtin: a potent insect antifeedant, Chem.-Eur. J. 14 (34) (2008) 10683-10704.

[36] A.J. Mordue, A.J. Nisbet, Azadirachtin from the neem tree Azadirachta indica: its action against insects, An. Soc. Entomol. Bras. 29 (2000) 615-632.

[37] P.T. Deota, P.R. Upadhyay, K.B. Patel, K.J. Mehta, B.V. Kamath, M.H. Mehta, Estimation and isolation of azadirachtin-A from neem [Azadirachta indica A. JUSS] seed kernels using high performance liquid chromatography, J. Liq. Chromatogr. Relat. Technol. 23 (14) (2000) 2225-2235.

[38] N. Kaushik, Determination of azadirachtin and fatty acid methyl esters of Azadirachta indica seeds by HPLC and GLC, Anal. Bioanal. Chem. 374 (7-8) (2002) 1199-1204.

[39] S.V. Ley, A.A. Denholm, A. Wood, The chemistry of azadirachtin, Nat. Prod. Rep. 10 (2) (1993) 109-157.

[40] S. Johnson, E.D. Morgan, Comparison of chromatographic systems for triterpenoids from neem (Azadirachta indica) seeds, J. Chromatogr. A 761 (1-2) (1997) 53-63.

[41] S. Chaudhary, R.K. Kanwar, A. Sehgal, D.M. Cahill, C.J. Barrow, R. Sehgal, J.R. Kanwar, Progress on Azadirachta indica based biopesticides in replacing synthetic toxic pesticides, Front. Plant Sci. 8 (2017).

[42] S.J. Boeke, M.G. Boersma, G.M. Alink, J.J.A. van Loon, A. van Huis, M. Dicke, I.M.C.M. Rietjens, Safety evaluation of neem (Azadirachta indica) derived pesticides, J. Ethnopharmacol. 94 (1) (2004) 25-41.

[43] C.M. Oulhaci, B. Denis, S. Kilani-Morakchi, J.C. Sandoz, L. Kaiser, D. Joly, N. Aribi, Azadirachtin effects on mating success, gametic abnormalities and progeny survival in Drosophila melanogaster (Diptera), Pest Manag. Sci. 74 (1) (2018) 174-180.

[44] R.B. Raizada, M.K. Srivastava, R.A. Kaushal, R.P. Singh, Azadirachtin, a neem biopesticide: subchronic toxicity assessment in rats, Food Chem. Toxicol. 39 (5) (2001) 477-483.

[45] M.K. Srivastava, R.B. Raizada, Assessment of embryo/fetotoxicity and 
teratogenicity of azadirachtin in rats, Food Chem. Toxicol. 39 (10) (2001) 1023-1027.

[46] S.I. Stalin, S. Kiruba, S.S.M. Das, A comparative study on the toxicity of a synthetic pyrethroid, deltamethrin and a neem based pesticide, azadirachtin to Poecilia reticulata Peters 1859 (Cyprinodontiformes: poeciliidae), Turk. J. Fish. Quat. Sci. 8 (1) (2008) 1-5.

[47] E.U. Winkaler, T.R.M. Santos, J.G. Machado-Neto, C.B.R. Martinez, Acute lethal and sublethal effects of neem leaf extract on the neotropical freshwater fish Prochilodus lineatus, Comp. Biochem. Physiol. C-Toxicol. Pharmacol. 145 (2) (2007) 236-244.

[48] G. Harish Kumar, K.V.P. Chandra Mohan, A. Jagannadha Rao, S. Nagini, Nimbolide a limonoid from Azadirachta indica inhibits proliferation and induces apoptosis of human choriocarcinoma (BeWo) cells, Investig. New Drugs 27 (3) (2009) 246-252.

[49] C. Binder, D. Marx, L. Binder, A. Schauer, W. Hiddemann, Expression of Bax in relation to Bcl-2 and other predictive parameters in breast cancer, Ann. Oncol. 7 (2) (1996) 129-133.

[50] M. Thoh, B. Babajan, P.B. Raghavendra, C. Sureshkumar, S.K. Manna, Azadirachtin interacts with retinoic acid receptors and inhibits retinoic acid-mediated biological responses, J. Biol. Chem. 286 (6) (2011) 4690-4702.

[51] A.B. Isah, Y.K.E. Ibrahim, E.O. Iwalewa, Evaluation of the antimalarial properties and standardization of tablets of Azadirachta indica (Meliaceae) in mice, Phytother. Res. 17 (7) (2003) 807-810.

[52] P. Ambrosino, R. Fresa, V. Fogliano, S.M. Monti, A. Ritieni, Extraction of azadirachtin A from neem seed kernels by supercritical fluid and its evaluation by HPLC and LC/MS, J. Agric. Food Chem. 47 (12) (1999) 5252-5256.

[53] H. Rembold, Secondary plant products in insect control, with special reference to the azadirachtins, in: W. Engels, W.H. Clark, A. Fischer, P.J.W. Olive, D.F. Went (Eds.), Advances in Invertebrate Reproduction, Elsevier, Amsterdam, 1984, pp. 481-491.

[54] H. Rembold, H. Forster, C.H. Czoppelt, P.J. Rao, K.P. Sieber, The azadirachtins: a group of insect regulators from Neem tree, in: H. Schmutterer, K.R.S. Ascher (Eds.), Natural Pesticides from Neem and Other Tropical Plants, GTZ Press, Eschborn, 1984, pp. 153-162.

[55] E.D. Morgan, Natural pesticides from the neem tree (Azadirachta indica A. Juss), in: H. Schmutterer, K.R.S. Ascher, H. Rembold (Eds.), Proceedings of the First International Neem Conference, GTZ Press, Eschborn, 1982, pp. 43-52.

[56] R.B. Yamasaki, J.A. Klocke, Structure bioactivity relationships of azadirachtin, a potential insect control agent, J. Agric. Food Chem. 35 (4) (1987) 467-471.

[57] P.M. Dewick, The mevalonate and methylerythritol phosphate pathways: terpenoids and steroids, in: P.M. Dewick (Ed.), Medicinal Natural Products: A Biosynthetic Approach, John Wiley \& Sons, Ltd., West Sussex, United Kingdom, 2009, pp. 187-310.

[58] R. Aerts, A.J. Mordue, Feeding deterrence and toxicity of neem triterpenoids, J. Chem. Ecol. 23 (9) (1997) 2117-2132.

[59] C. Devakumar, R. Kumar, Total synthesis of azadirachtin: a chemical odyssey, Curr. Sci. 95 (5) (2008) 573-575.

[60] G.E. Veitch, E. Beckmann, B.J. Burke, A. Boyer, C. Ayats, S.V. Ley, A relay route for the synthesis of azadirachtin, Angew. Chem.-Int. Edit. 46 (40) (2007) 7633-7635.

[61] B. Sultana, F. Anwar, M. Ashraf, Effect of extraction solvent/technique on the antioxidant activity of selected medicinal plant extracts, Molecules 14 (6) (2009) 2167-2180.

[62] M. Teresa González-Garza, M. Codinach, C. Alcaraz, J. Moreno-Cuevas, P. Caerranza-Rosales, D.E. Cruz-Vega, Effect of Azadirachta indica leaf methanol extracts on stem cell reproduction, Fitoterapia 78 (3) (2007) 235-237.

[63] G.C. Jadeja, R.C. Maheshwari, S.N. Naik, Extraction of natural insecticide azadirachtin from neem (Azadirachta indica A. Juss) seed kernels using pressurized hot solvent, J. Supercrit. Fluids 56 (3) (2011) 253-258.

[64] S. Tonk, R. Bartarya, K.M. Kumari, V.P. Bhatnagar, S.S. Srivastava, Effective method for extraction of larvicidal component from leaves of Azadirachta indica and Artemisia annua Linn, J. Environ. Biol. 27 (1) (2006) 103-105.

[65] P. Sithisarn, R. Supabphol, W. Gritsanapan, Comparison of free radical scavenging activity of Siamese neem tree (Azadirachta indica A. Juss var. siamensis Valeton) leaf extracts prepared by different methods of extraction, Med. Princ. Pract. 15 (3) (2006) 219-222.

[66] P. Sithisarn, R. Supabphol, W. Gritsanapan, Antioxidant activity of Siamese neem tree (VP1209), J. Ethnopharmacol. 99 (1) (2005) 109-112.

[67] A.P. Jarvis, E.D. Morgan, Analysis of small samples of limonoids of neem (Azadirachta indica) using solid phase extraction from tissue culture, Phytochem. Anal. 11 (3) (2000) 184-189.

[68] J.A.M. de Paula, L.F. Brito, K. Caetano, M.C.D. Rodrigues, L.L. Borges, E.C. da Conceicao, Ultrasound-assisted extraction of azadirachtin from dried entire fruits of Azadirachta indica A. Juss. (Meliaceae) and its determination by a validated HPLCPDA method, Talanta 149 (2016) 77-84.

[69] D.R. Schroeder, K. Nakanishi, A simplified isolation procedure for azadirachtin, J. Nat. Prod. 50 (2) (1987) 241-244.

[70] V. Sharma, S. Walia, J. Kumar, M.G. Nair, B.S. Parmar, An efficient method for the purification and characterization of nematicidal azadirachtins A, B, and H, using MPLC and ESIMS, J. Agric. Food Chem. 51 (14) (2003) 3966-3972.

[71] J. Dai, V.A. Yaylayan, G.S. Vijaya Raghavan, J.R. Parè, Z. Liu, Multivariate calibration for the determination of total azadirachtin-related limonoids and simple terpenoids in neem extracts using vanillin assay, J. Agric. Food Chem. 49 (3) (2001) 1169-1174.

[72] M.R. Forim, M.F.d.G.F. da Silva, Q.B. Cass, J.B. Fernandes, P.C. Vieira, Simultaneous quantification of azadirachtin and 3-tigloylazadirachtol in brazilian seeds and oil of Azadirachta indica: application to quality control and marketing,
Anal. Methods 2 (7) (2010) 860-869.

[73] C.M. Boursier, D. Bosco, A. Coulibaly, M. Negre, Are traditional neem extract preparations as efficient as a commercial formulation of azadirachtin A? Crop Prot. 30 (3) (2011) 318-322.

[74] S. Ismadji, A. Kurniawan, Y.H. Ju, F.E. Soetaredjo, A. Ayucitra, L.K. Ong, Solubility of azadirachtin and several triterpenoid compounds extracted from neem seed kernel in supercritical CO2, Fluid Phase Equilib. 336 (0) (2012) 9-15.

[75] L. Song, J. Wang, Q. Gao, X.J. Ma, Y.W. Wang, Y.Y. Zhang, H. Xun, X. Yao, F. Tang, Simultaneous determination of five azadirachtins in the seed and leaf extracts of Azadirachta indica by automated online solid-phase extraction coupled with LC-QTOF-MS, Chem. Cent. J. 12 (2018) 85.

[76] J. Dai, V.A. Yaylayan, G.S.V. Raghavan, J.R. Parè, Extraction and colorimetric determination of azadirachtin-related limonoids in neem seed kernel, J. Agric. Food Chem. 47 (9) (1999) 3738-3742.

[77] S. Schütz, I. Wengatz, M.H. Goodrow, S.J. Gee, H.E. Hummel, B.D. Hammock, Development of an enzyme-linked immunosorbent assay for azadirachtins, J. Agric. Food Chem. 45 (6) (1997) 2363-2368.

[78] K. Ermel, E. Pahlich, H. Schmutterer, Comparison of azadirachtin content of neem seeds from ecotypes of asian and african origin, in: H. Schmutterer, K.R.S. Ascher (Eds.), Proceedings of the Second International Neem Conference, GTZ Press, Eschborn, 1984, pp. 91-93.

[79] H.-P. Huang, E.D. Morgan, Analysis of azadirachtin by supercritical-fluid chromatography, J. Chromatogr. A 519 (1) (1990) 137-143.

[80] R. Thejavathi, S.R. Yakkundi, B. Ravindranath, Determination of azadirachtin by reversed-phase high-performance liquid chromatography using anisole as internal standard, J. Chromatogr. A 705 (2) (1995) 374-379.

[81] O. Schaaf, A.P. Jarvis, S.A. van der Esch, G. Giagnacovo, N.J. Oldham, Rapid and sensitive analysis of azadirachtin and related triterpenoids from neem (Azadirachta indica) by high-performance liquid chromatography-atmospheric pressure chemical ionization mass spectrometry, J. Chromatogr. A 886 (1-2) (2000) 89-97.

[82] M.R. Forim, A.P. Matos, M.F.G.F. Silva, Q.B. Cass, P.C. Vieira, J.B. Fernandes, Uso de CLAE no controle de qualidade em produtos comerciais de nim: reprodutibilidade da ação inseticida, Quím. Nova 33 (2010) 1082-1087.

[83] C.J. Hull Jr., W.R. Dutton, B.S. Switzer, Quantitation of azadirachtins in insecticidal formulations by high-performance liquid chromatography, J. Chromatogr. A 633 (1-2) (1993) 300-304.

[84] K.M.S. Sundaram, J. Curry, High performance liquid chromatographic method for the analysis of azadirachtin in two commercial formulations and neem oil, J. Environ. Sci. Health Part B-Pestic. Contam. Agric. Wastes 28 (2) (1993) 221-241.

[85] E. Melwita, Y.-H. Ju, Separation of azadirachtin and other limonoids from crude neem oil via solvent precipitation, Sep. Purif. Technol. 74 (2) (2010) 219-224.

[86] M. Saxena, K. Ravikanth, A. Kumar, A. Gupta, B. Singh, A. Sharma, Purification of Azadirachta indica seed cake and its impact on nutritional and antinutritional factors, J. Agric. Food Chem. 58 (8) (2010) 4939-4944.

[87] P. Caboni, M. Cabras, A. Angioni, M. Russo, P. Cabras, Persistence of azadirachtin residues on olives after field treatment, J. Agric. Food Chem. 50 (12) (2002) 3491-3494.

[88] G. Sarais, P. Caboni, E. Sarritzu, M. Russo, P. Cabras, A simple and selective sethod for the measurement of azadirachtin and related azadirachtoid levels in fruits and vegetables using liquid chromatography electrospray ionization tandem mass spectrometry, J. Agric. Food Chem. 56 (9) (2008) 2939-2943.

[89] K. Rangiah, B.A. Varalaxmi, M. Gowda, UHPLC-MS/SRM method for quantification of neem metabolites from leaf extracts of Meliaceae family plants, Anal. Methods 8 (9) (2016) 2020-2031.

[90] H. Rembold, Isomeric azadirachtins and their mode of action, in: M. Jacobson (Ed.), Focus on Phytochemical Pesticides, CRC Press, Boca Raton, 1989, pp. 47-67.

[91] S. Grimalt, D.G. Thompson, M. Coppens, D.T. Chartrand, T. Shorney, J. Meating, T. Scarr, Analytical study of azadirachtin and 3-tigloylazadirachtol residues in foliage and phloem of hardwood tree species by liquid chromatography-electrospray mass spectrometry, J. Agric. Food Chem. 59 (15) (2011) 8070-8077.

[92] A. Klenk, M. Bokel, W. Kraus, 3-2-Methylcrotonoylazadirachtol, an insect growthregulating constituent of Azadirachta indica, J. Chem. Soc. Chem. Commun. (7) (1986) 523-524.

[93] E. Coventry, E.J. Allan, Microbiological and chemical analysis of neem (Azadirachta indica) extracts: new data on antimicrobial activity, Phytoparasitica 29 (5) (2001) $441-450$.

[94] G. Prakash, C.J.S.K. Emmannuel, A.K. Srivastava, Variability of azadirachtin in Azadirachta indica (neem) and batch kinetics studies of cell suspension culture, Biotechnol. Bioprocess Eng. 10 (3) (2005) 198-204.

[95] I.E. Elteraifi, A. Hassanali, Oil and azadirachtin contents of neem (Azadirachta in dica A. Juss) seed kernels collected from trees growing in different habitats in Sudan, Int. J. Biol. Chem. Sci. 5 (3) (2011) 1063-1072.

[96] D. Djibril, F. Mamadou, V. Gérard, M.C. Geuye, S. Oumar, R. Luc, Physical characteristics, chemical composition and distribution of constituents of the neem seeds (Azadirachta indica A. Juss) collected in Senegal, Res. J. Chem. Sci. 5 (7) (2015) 52-58.

[97] M. Rodrigues, R.A. Festucci-Buselli, L.C. Silva, W.C. Otoni, Azadirachtin biosynthesis induction in Azadirachta indica A. Juss cotyledonary calli with elicitor agents, Braz. Arch. Biol. Technol. 57 (2) (2014) 155-162.

[98] J.C.T. Silva, G.N. Jham, R.D.L. Oliveira, L. Brown, Purification of the seven tetranortriterpenoids in neem (Azadirachta indica) seed by counter-current chromatography sequentially followed by isocratic preparative reversed-phase high-performance liquid chromatography, J. Chromatogr. A 1151 (1-2) (2007) 203-210. 